\title{
LA EXPULSIÓN DE UN PROFESO JESUITA: EL P. HERNANDO DE MORALES (1576-1631) ${ }^{1}$
}

\author{
POR \\ JOSÉ MANUEL DÍAZ BLANCO \\ Universidad de Huelva
}

A tutti i cari amici dell'Archivum Romanum Societatis lesu

\section{RESUMEN}

Este artículo estudia la vida y el pensamiento del P. Hernando de Morales, SI. Morales fue un brillante jesuita que perdió su vocación cuando comprendió que no podía soportar la obediencia a sus superiores. Durante el reinado de Felipe IV, fue un amigo político del conde duque de Olivares y defendió la política real. A causa de esto, fue expulsado de la Compañía de Jesús en 1631.

1 Este trabajo ha sido realizado gracias al Programa de Ayudas Posdoctorales en el Extranjero del Ministerio de Educación, Cultura y Deporte de España, expediente 2010-0396, aplicado a la Universidad de Sevilla como centro contratante y a la Scuola Normale Superiore de Pisa como centro receptor, donde el trabajo se ha desarrollado bajo la dirección del prof. Adriano Prosperi. Las abreviaturas empleadas en él son: ARSI: Archivum Romanum Societatis lesu (AH: Assistentia Hispaniae, Baetica: Provincia Baetica), BDC: Biblioteca Diocesana de Córdoba, BUS: Biblioteca Universitaria de Sevilla, DHCJ: O’Neill, Ch. y Domínguez, J. Mª (dirs.) 2011. Diccionario Histórico de la Compañía de Jesús: Madrid-Roma: Universidad Comillas-IHSI, RAH: Real Academia de la Historia. Agradezco a José Antonio Ollero Pina y Mauro Brunello la ayuda que me han prestado para mejorar sustancialmente este texto. 


\section{PALABRAS CLAVE}

Hernando de Morales; Compañía de Jesús (gobierno); expulsión de jesuitas; conde duque de Olivares; crisis del siglo XVII.

\section{THE EXPULSION OF A JESUIT PRIEST: F. HERNANDO DE MORALES (1576-1631)}

\section{ABSTRACT}

This article focuses on the life and thought of $F$. Hernando de Morales, SJ. Morales was a brilliant Jesuit who lost his vocation when he realized to be incapable to obey to his superiors. During the reign of Philip IV he was a political friend of the Count Duke of Olivares and defended the royal policy. Because of that in 1631 he was expelled from the Society of Jesus.

\section{KEY WORDS}

Hernando de Morales; Society of Jesus (government); expulsion of Jesuits; Count Duke of Olivares; XVIIth century crisis.

$\begin{array}{ll}\text { Recibido/Received } & 14-03-2013 \\ \text { Aceptado/Accepted } & 16-06-2014\end{array}$

EI P. Hernando de Morales, SI, ha dejado algunas huellas leves en los libros de Historia. Su nombre ha figurado con un rango secundario dentro de los conocidos repertorios bibliográficos del $\mathrm{P}$. Carlos Sommervogel y José Simón Díaz; ${ }^{2}$ más allá de esta simple mención, sólo don Antonio Domínguez Ortiz parece haber reparado en él para construir un discurso histórico coherente, pero sin detenerse en los detalles de su trayectoria individual. En las Alteraciones andaluzas Domínguez Ortiz

2 Sommervogel, C. 1960 [1894]. Bibliothéque de la Compagnie de Jésus: V, 1.282 Lovaina: Biblioteca Jesuita; Simón Díaz, J. 1975. Jesuitas de los siglos XVI y XVII: escritos localizados: 204-205 Madrid: FUE, donde corresponden a Morales las entradas 888 y 889; Simón Díaz, J. 1992. Bibliografía de la Literatura Hispánica: XV, 344 Salamanca: CSIC, donde le corresponden a Morales las entradas 2.677-2.679. 
utilizó uno de los memoriales citados por Sommervogel y Simón Díaz, pero sólo porque en él podía detectarse la existencia de una conciencia crítica contra la política de la Monarquía en la Sevilla de 1630. En sus propias palabras, "lo que nos parece más interesante es que [Morales] se hace eco (para refutarlas) de "las objeciones del vulgo»". ${ }^{3}$ Esas "objeciones del vulgo" eran lo que importaba a Domínguez Ortiz.

Por supuesto, la suerte historiográfica del P. Morales es común a la de muchos otros hombres de mérito a quienes los servidores de Clío apenas alcanzan a considerar como merecerían. Sin embargo, en su caso, el sumergimiento en el olvido procede originalmente de una cancelación de la memoria deliberada, pergeñada por su propia orden, la Compañía de Jesús. El jesuita, como otros sevillanos de su tiempo, se integró en la red clientelar del conde duque de Olivares y sus escritos más polémicos no tuvieron otra intención que la de legitimar las políticas del Gobierno. Morales defendió la política reputacionista de la Monarquía y justificó las agresivas medidas fiscales que se derivaban de ella, sobre todo durante la crisis de 1629-1631, cuando el conflicto sucesorio en Mantua se mezcló con la guerra de Flandes. ${ }^{4}$ La Monarquía intentó hacer frente a este fenomenal reto reformando su aparato fiscal y para ello contó con la ayuda intelectual del P. Morales, que en ese sentido se opuso a la mayor parte del clero sevillano, enemigo recio de la creación del nuevo estanco de la sal en $1631 .{ }^{5}$

El precio que Morales pagó por apoyar la causa monárquica fue la expulsión de la Compañía de Jesús y, después, la damnatio memoriae. ${ }^{6}$

${ }^{3}$ Domínguez Ortiz, A. 1973. Alteraciones andaluzas 1647-1652: 44-45 Madrid: Narcea.

${ }^{4}$ Elliott, J.H. 1998. El conde duque de Olivares. El político en una época de decadencia: cap. 11 Barcelona: Grijalbo Mondadori, donde se define a esta crisis como la "gran depresión".

${ }^{5}$ Aldea Vaquero, Q. 1961. Iglesia y Estado en la España del siglo XVII: 40-44 Santander: U. Comillas y, posteriormente, 1990. "Política interior: oposición y resistencia. La resistencia eclesiástica”, en J. H. Elliott y Á. García Sanz (coords.), La España del Conde Duque de Olivares: 399-414. Valladolid: Universidad; Elliott. J. H. 1998: 475-478; Gelabert González, J. E. 2001. Castilla convulsa (1631-1652): 42-48 Madrid: Marcial Pons; Fortea Pérez, J. I. 2008. "La gracia y la fuerza: el clero, las ciudades y el fisco en la Monarquía Católica (1590-1664)", en J. I. Fortea y J. E. Gelabert (eds.), Ciudades en conflicto (siglos XVI-XVIII): 137-161. Valladolid: Junta de Castilla y León-Marcial Pons.

${ }^{6}$ La trayectoria de Morales guarda semejanzas relevantes con la de otro religioso sevillano contemporáneo a él, el mercedario fray Hernando de Santiago, estudiado ejemplarmente en Ollero Pina, J. A. 2011. "Cerrad el pico al "Pico de oro». Fr. Hernando de Santiago, un predicador político en la España de Felipe III", Erebea. Revista de Humanidades y Ciencias Sociales 1: 281-313. Como Morales, Santiago se enfrentó a los superiores de su orden y a 
Tal vez no fue un pago muy oneroso para él, que llevaba años sumido en una honda pérdida de vocación. Es curioso cómo la crisis política en la que se inmiscuyó solucionó la crisis espiritual en la que había estado inmerso durante muchísimo tiempo. Ésta no es tampoco una cuestión de interés menor. No se trata de escrudiñar morbosamente en el alma de un hombre cultivado como Morales, sino de entender cómo sus dudas exigieron un replanteamiento de la relación que lo unió a la Compañía de Jesús hasta el momento final de la expulsión.

La historiografía ha tratado muy marginalmente el problema de la expulsión de jesuitas de la Compañía. Resultaría excesivo presentarlo como un tabú dentro de los numerosos estudios sobre la orden, pero nadie podría negar que ha recibido una atención muy reducida. ${ }^{7}$ Esta escasez no tiene nada de extraño; la mecánica institucional de la Compañía se ha estudiado muy poco en general y este aspecto en concreto no es ninguna excepción, sino todo lo contrario. Al fin y al cabo, puede afirmarse que la expulsión o "dimisión" se trató de un proceso porcentualmente minoritario y realmente raro en los estratos superiores de la jerarquía ignaciana. ${ }^{8}$ Ahora bien, esa misma escasez, así como la aspereza de su propia naturaleza, podía otorgar a algunas expulsiones un carácter verdaderamente traumático a nivel interno. Cuando esas tensísimas circunstancias se generaban, los valores y los criterios con los

diversos estamentos e instituciones, manteniendo además una posición política pública, que fue contraria a la política pacifista del duque de Lerma. En general, la tendencia a inmiscuirse en la vida política fue muy marcada en el clero del Antiguo Régimen, según ha puesto de relieve Domínguez Ortiz, A. 1985. Las clases privilegiadas en el Antiguo Régimen: cap. 17 Madrid: Istmo.

7 Una experta en historia jesuita como Sabina Pavone ha considerado recientemente este problema como una cuestión historiográfica nueva en 2011. "I dimessi dalla Compagnia negli anni del generalato di Francesco Borgia: una nuova questione storiografica", en E. García Hernán y María del Pilar Ryan (eds.), Francisco de Borja y su tiempo. Política, religión y cultura en la Edad Moderna: 465-479. Valencia-Roma: Albatros-IHSI. Entre las escasas referencias que podrían citarse: Astrain, A. 1916. Historia de la Compañía de Jesús en la asistencia de España. Tomo V: Vitelleschi, Carafa, Piccolomini, 1615-1652: 59-66 Madrid: Razón y Fe; Lynn Martin, A. 1986. "Vocational Crises and the Crisis in Vocations among Jeuits in France during the Sixteenth Century", The Catholic Historical Review 72/2: 201-221; O'Neill, Ch. y Domínguez, J. Ma . (dirs.) 2011. Diccionario Histórico de la Compañía de Jesús: Madrid-Roma: Universidad Comillas-IHSI (DHCJ), III, 2.665, que incluye dentro de la voz miembros de la CJ un epígrafe dedicado a la dimisión que, a su vez, remite a una bibliografía poco extensa.

8 Así lo indican los catálogos de "dimissi" que conservan algunos catálogos trienales y el registro incompleto (1573-1640) que se conserva en ARSI, Historiae Societatis, vol. 54. Esta documentación permitiría realizar un cierto análisis cuantitativo del fenómeno en algunas provincias para algunas épocas. 
que se gobernaba la Compañía de Jesús afloraban con una pulcritud preciosa para el historiador.

Las Constituciones pretendieron codificar los aspectos esenciales de la expulsión de miembros de la orden. El primer rasgo del proceso era su universalidad, atemperada por un doble sentido de prudencia y progresividad en su aplicación. Cualquier jesuita podía verse algún día en esa situación, pero se tenía muy claro que ésta debía responder a una decisión tomada tras mucha reflexión y que, conforme mayor fuese la jerarquía interna del individuo, más exigentes tendrían que ser los requisitos a la hora de asumirla. En el caso de los profesos de cuatro votos, la élite jesuita, la expulsión debía llegar en situaciones extremas, en las que hubiese quedado demostrado que no había más opción posible. Por supuesto, sólo el padre general en Roma tenía capacidad para separar de la Compañía a un profeso, por lo que la participación de los superiores provinciales y locales dependería estrictamente de las instrucciones que aquél les hiciese llegar, sin poder tomar resolución alguna por sí mismos. ${ }^{9}$

La teoría estaba razonablemente clara, pero ¿era suficiente para afrontar la praxis del problema? En 1603, el P. Melchor de Valdepedrosa no lo consideraba así y en nombre de la provincia de Castilla solicitó a Acquaviva una instrucción que desarrollase el contenido de las Constituciones, pues "ayudaría mucho para la práctica". El general prometió una "con la qual se proceda con mayor claridad en negocio tan importante", ${ }^{10}$ pero era difícil que este tipo de situaciones se normativizase con tanta eficacia como para que dejase de generar controversia, sobre todo cuando se trataba de los niveles altos de la jerarquía. Ése fue el caso del P. Morales, expulsado cuando era ya profeso de cuatro votos en 1631, durante el gobierno del general Muzio Vitelleschi. Su peripecia fue una de las que san Ignacio de Loyola esperó escasas. ¿Por qué sucedió? ¿Fue su comportamiento tan afrentoso contra Dios o contra la Compañía? ¿Controló Vitelleschi el proceso tan estrechamente como se esperaba? ¿Actuaron los superiores provinciales y locales tan disciplinadamente? En definitiva, ¿el caso Morales se ajustó en la práctica a los procedimientos teóricos expresados en la documentación del Instituto?

${ }^{9}$ Constituciones, parte II.

10 Archivum Romanum Societatis lesu (ARSI), Congregationes Provinciarum, vol. 50. 


\section{UN JESUITA EJEMPLAR (1592-1611)}

Hernando de Morales nació en Jerez de la Frontera en 1576 y entró en la Compañía de Jesús en 1592, a los dieciséis años de edad. ${ }^{11}$ Siguió un cursus honorum modélico, paradigmático de la mejor carrera jesuita: ${ }^{12}$

- Novicio (1592-1594 aprox.). Morales realizó su probación en Montilla, cuyo domicilio era entonces colegio y noviciado simultáneamente.

- Escolar (1595-1601 aprox.). Morales estudió en el colegio de Córdoba el septenio de Artes y Teología.

- Sacerdote (1601-1610 aprox.). Morales estudió durante un año en el seminario de Sevilla, se ordenó sacerdote y, antes de jurar como profeso, ejerció diversos ministerios, entre ellos el magisterio del Latín en el colegio de Baeza.

- Profeso (1610-1631). Tras jurar los cuatro votos en la casa profesa de Sevilla, Morales llegó a la cúspide de la jerarquía interna jesuita. Como profeso ejerció en varios domicilios de la provincia de Andalucía algunos de los ministerios más relevantes que practicaba la orden: fue confesor de hombres y mujeres, prefecto de casos de conciencia, predicador, profesor y lector de Artes, Teología y Filosofía, etc.

${ }^{11}$ Esta información se colige de los catálogos trienales de la provincia de Andalucía desde 1593 hasta 1628, consultables en ARSI, Baetica, vols. 8 y 9-I. Perteneció a una familia de la oligarquía local, estudiada en conjunto por González Beltrán, J. 1998. Honor, riqueza y poder. Los veinticuatro de Jerez de la Frontera en el siglo XVIII: Jerez: Ayuntamiento y 2001. "Constitución y reproducción de una oligarquía urbana: los veinticuatro de Jerez de la Frontera en el siglo XVII". Revista de Historia Moderna: Anales de la Universidad de Alicante 19: 355-384.

12 Morales, en los memoriales que escribió por el colegio de Salamanca contra Leonor Bermúdez, resumió este cursus honorum: "la profession en la Conpañia no se dá tan presto, sino que passan 14. 15 i mas años, [...] porque en dos años de noviciado, siete de estudios, i otro de tercera probacion, que dura un año despues de acabados los estudios, se passan diez años, i luego comiença a exercer ministerios, i mostrar si sus talentos son dignos de que le den la profession": Biblioteca Universitaria de Sevilla (BUS), 110/141(30 y 31); Por el colegio real de la Compañia de lesvs de Salamanca con Doña Leonor Bermudez, mujer de Iuan Baptista del Canpo, ausente en las Indias, s.f. y Segvnda. Por el real colegio de Salamanca en el pleito con doña Leonor Bermvdez, mvger de Iuan Bautista del Canpo, ausente en Indias, s.f. 
Pese a la abundante documentación jesuita, resulta difícil penetrar en los primeros años de Morales en la disciplina ignaciana. Los fondos del gobierno romano presentan una cierta progresividad y suelen contener mayor información de cada jesuita conforme mayor es su posición dentro de la jerarquía interna. Todo lo más a lo que puede llegarse es a una reflexión genérica sobre lo que aquella etapa inicial supuso. A Morales lo enjuiciaron repetidamente a lo largo de veinte años; se analizó su capacidad intelectual y su preparación, pero también sus valores cristianos y los específicamente jesuitas, dentro de los cuales era fundamental la "indiferencia" en el obedecer a sus superiores. De haberse detectado en él algún inconveniente realmente grave, no hubiese superado el noviciado ni después hubiese permanecido en la Compañía logrando las mejores perspectivas personales. Después de un proceso de integración largo y exigente, Morales fue propuesto para entrar dentro de la élite jesuita: los profesos de cuatro votos.

Morales profesó en la casa profesa de Sevilla el 31 de julio de 1610. En la ceremonia leyó dos papeles con sus votos que afortunadamente se han conservado hasta hoy. Ciertamente, el texto que contienen es formulario, una copia fiel del modelo general de profesión que recogen las Constituciones. ${ }^{13}$ Pero eso no es óbice para que veamos en ellos una muestra preciosa de las convicciones íntimas de Morales en aquella etapa de su vida. De seguro, Morales había reflexionado mucho sobre su contenido en los días previos, según exigía la normativa jesuita, y lo había aceptado. Como consecuencia, juró ante Dios, la Virgen y la curia celestial "perpetuam Paupertatem, Castitatem \& obedientiam; \& secundum eam peculiarem curam circa puerorum eruditionem, iuxta formam viuendi in litteris Apostolicis societatis IESV, \& in eius constitutionibus contentam". Adicionalmente, y esto es lo característico que define a los profesos jesuitas, prometió "specialem Obedientiam summo Pontifici, circa Missiones". ${ }^{14}$

¿Quién hubiera podido decir en aquel verano de 1610 que el hombre que juraba en la casa profesa de Sevilla se convertiría en un sujeto problemático e indeseado dentro de la Compañía? Había protagonizado una probación arquetípica, que incluso debió de ser brillante; había culminado sus estudios sin problemas, había ejercido dignamente sus primeros ministerios como sacerdote y había alcanzado el nivel más elevado al que podía escalarse dentro de la jerarquía jesuítica, el de profeso de cuatro votos. Él mismo recordó en cierta ocasión lo difícil que era lograr todo eso: "en la Conpañia se concede la profession despues de muchas experiencias, pruebas, i prendas, i partes,

${ }^{13}$ Constituciones, parte $\mathrm{V}$, cap. 3.

${ }^{14}$ ARSI, Assistentia Hispaniae (AH), vol. 3-II, fols. 538 y 541. 
que requieren muchos años de vida religiosa, mucho estudio, i trabajo". ${ }^{15}$ Incluso Claudio Acquaviva lo felicitó poco después por su buena integración en la Compañía. ${ }^{16}$ Parecía destinado a ejercer los ministerios más relevantes que hubiera oportunidad de encargarle $y$, sin embargo, sucedió todo lo contrario. Poco tiempo después del juramento, Morales comenzó a tener problemas con sus superiores más inmediatos y los conflictos en los que se inmiscuyó no tardaron en resonar desfavorablemente en Roma. Era el comienzo de una larga historia en la que su nombre apareció demasiadas veces vinculado a situaciones de división interna y discusión. Llegó el día en el que la cuerda se tensó demasiado. Y se rompió.

\section{CRISIS PERSONAL Y PÉRDIDA DE LA VOCACIÓN (1613-1615)}

El primer paso de aquel camino se registró en Granada el año de 1613. Morales escribió varias cartas a Claudio Acquaviva protestando por "algunos recelos y señales de menos confiança" que, según su propio testimonio, le demostraban el rector Juan Pérez ${ }^{17}$ y demás superiores del colegio. ${ }^{18}$ El general le respondió en términos paternales, intentando consolarlo, ${ }^{19}$ pero antes de que Morales pudiese leer sus suaves palabras, escribió por segunda vez a Roma ${ }^{20}$ Es posible que su conflicto con el rector de Granada se hubiese endurecido, puesto que en esta ocasión llegó más lejos que la vez anterior y solicitó a Acquaviva que le permitiese abandonar la Compañía de Jesús para ingresar en otra orden. Era la primera vez que Morales solicitaba tal cosa, aunque no sería la última; tres años después de su profesión, había perdido la vocación jesuita.

${ }_{15}$ Morales, Por el colegio real, fol. 19r.

${ }^{16}$ ARSI, Baetica, vol. 4-I; Acquaviva a Morales, Roma, 29 de marzo de 1611.

17 Juan Pérez, natural de Montilla. Nació hacia 1566, entró en la Compañía hacia 1581 y profesó el 8 de septiembre de 1595: ARSI, Baetica, vol. 8.

18 Estas cartas de Morales no se conservan, pero su contenido, fecha aproximada y destinatario pueden conocerse gracias a las respuestas de Acquaviva, que se citan a continuación. Ésta es una situación constante, puesto que el ARSI conserva gran parte de los registros de las cartas enviadas por el general a las provincias, pero ha desechado muchos de los originales que llegaban a Roma.

${ }^{19}$ ARSI, Baetica, vol. 4-II; Acquaviva a Morales, Roma, 10 de septiembre y 8 de octubre de 1613 .

20 Morales escribió esta segunda carta en septiembre, mientras que Acquaviva no pudo responder a su primera carta hasta el 8 de octubre. 
Acquaviva denegó su petición. Escribió a los superiores de Andalucía para que se preocupasen mucho por el $\operatorname{caso}^{21} \mathrm{y}$, por supuesto, escribió también al propio Morales. En esta nueva misiva lo conminó a seguir recorriendo el "camino de la perfectión" y le insistió en lo mismo que ya antes le había dicho; atribuyó a "melancolía" la crisis que estaba padeciendo y lo animó a luchar por la "gracia de su vocación". No iba a dejarle opción a abandonar la Compañía. Aunque el texto aún estaba escrito en un tono paternal, terminó con una admonición que dejaba traslucir decepción: "V[uestra] r[everencia] podría ahorrar buena parte de los desgustos atendiendo más a lo interior y crea q[ue] el r[ect]or no puede dexar de hazer su officio, so pena de dar cuenta muy estrecha a n[uest]ro S[eño]r. ${ }^{22}$

Morales no se alivió con el tono afectivo de la primera carta ni se amilanó por el acento más riguroso de la segunda. Según parece, en enero de 1614 volvió a escribir a Roma y lo hizo con la misma amargura y en los mismos términos que en los meses anteriores. Acquaviva le respondió en mayo, con pesar. Atribuyó la terquedad del problema a la acción del Diablo, definido como el "común enemigo", e instó a Morales a resistirse mediante la oración, pidiendo a Dios que "le conceda gracia para proseguir en la de su primera vocación". Decir eso equivalía a negarle de nuevo la salida de la orden; Acquaviva no dejó a Morales más posibilidades que la meditación, la mortificación y la conversación íntima con quien pudiese ayudarle a encontrar quietud. Si se esforzaba en ello, "desaparecerán las tinieblas que causan en su alma tanta melancolía y con el diu[in] ${ }^{\circ}$ fauor conseguirá la desseada paz y gozo [e]sp[irit]ual". ${ }^{23}$ Por supuesto, Acquaviva impuso su voluntad gracias a la autoridad suprema de la que gozaba dentro de la Compañía, pero además se sintió legitimado para hacerlo por cuanto Morales, pese a todo lo que estaba sucediendo, no había dejado de ponerse a disposición de él. De tal manera se lo refirió al $P$. Hernando Ponce de León, ${ }^{24}$ que por aquel entonces había iniciado una visita a la provincia andaluza: ${ }^{25}$ "Como al

${ }^{21}$ ARSI, Baetica, vol. 4-II; Acquaviva a Juan Pérez, Alonso de Escobar y Marcos del Castillo, Roma, 5 de noviembre de 1613.

${ }^{22}$ ARSI, Baetica, vol. 4-II; Acquaviva a Morales, Roma, 5 de noviembre de 1613. Acquaviva escribió a Morales una nueva carta con el ordinario de 3 de diciembre de 1613 en la que le aseguró que no había enseñado sus escritos a nadie. 1614.

${ }^{23}$ ARSI, Baetica, vol. 4-II; Acquaviva a Morales, Roma, 20 de mayo de

24 Hernando Ponce nació en 1561 en Espera (Cádiz) y murió el 17 de febrero de 1622. Entró en la Compañía el 27 de junio de 1577, se ordenó sacerdote en 1586 y profesó 12 de agosto de 1595. DHCJ, IV, pp. 3.187-3.188.

${ }^{25}$ El inicio efectivo de la visita se sitúa en la casa profesa de Sevilla el 7 de noviembre de 1613, según detalla el documento editado en Herrera Puga, 
cabo [Morales] se remite y pone en n[uest]ras manos, se le responde animándole a proseguir en la gracia de su primera vocación". Ponce tendría que informarse del extraño problema del P. Morales, que escribía a Roma "alegando su poco gusto en la Comp[añí] y pidiendo mudança". ${ }^{26}$

No parece que Morales se conformase con el consuelo de la oración, ya que las siguientes referencias que se encuentran en la correspondencia de Acquaviva reflejan el comportamiento de una persona cuya vocación se había debilitado. Su actitud llegó a ser realmente indignante después de la muerte de Acquaviva, cuando quiso aprovechar la interinidad gubernativa posterior para conseguir sus fines personales, que seguían apuntando hacia la salida de la Compañía. Hasta la proclamación de Vitelleschi como nuevo general, la Compañía fue gobernada por el P. Fernando Alber en calidad de vicario general. ${ }^{27}$ Alber juzgó el problema Morales a través de los ojos del P. Ponce, que después de terminar su visita fue nombrado provincial de la Bética. ${ }^{28}$ Éste, pese al conocimiento que tenía del difícil carácter de Morales, empezó a juzgarle con poca severidad. Al parecer, entendió que era suficiente con "auerle quitado la lectura", ${ }^{29}$ a lo que Alber sólo creyó oportuno añadir que "conuiene irle ayudando". ${ }^{30}$ Era una solución ingenua, porque mientras tanto Morales no dejó de incurrir en bajezas vulgarísimas para salirse con la suya.

La estrategia de Morales fracasó por su propia debilidad. En un primer momento, intentó convencer a Ponce de que Acquaviva sí le

P. 1971. Los jesuitas en Sevilla en tiempo de Felipe III: 68. Granada: Universidad.

${ }^{26}$ ARSI, Baetica, vol. 4-II; Acquaviva a Hernando Ponce, Roma, 20 de mayo de 1614.

${ }^{27}$ Astrain, Historia, V, p. 1.

${ }^{28}$ El hecho también se menciona en Herrera Puga, P. 1971: 76.

${ }^{29}$ La expresión se refiere a la lectura de Teología y otras materias en el colegio, un aspecto que dolió mucho a Morales por su afición a este tipo de actividades. El caso coincide muchísimo en la materia y la actitud de las partes con el que protagonizó el P. Antonio de Lerma, contemporáneo de Morales, que también terminó expulsado de la Compañía: Astrain, A. 1916: 60-62, que dice "enseñaba este Padre Teología en el colegio de Salamanca, y por los años de 1630 juzgaron los Superiores que no debía continuar en aquel colegio por la inquietud de carácter que mostraba y por las ideas extravagantes [...]. Retiráronle, pues, de la cátedra y le mandaron ir a Burgos. Indignóse bravamente el P. Lerma, y escribió al P. General quejándose de que los Superiores le habían quitado la honra, destituyéndole de aquella cátedra, que por entonces se miraba como indicio de ingenio y sabiduría" (p. 60).

${ }^{30}$ ARSI, Baetica, vol. 4-I; Alber a Hernando Ponce, Roma, 24 de febrero de 1615. 
había concedido a última hora la licencia para mudarse a otra orden y, por tanto, quiso forzarle a que ejecutara la medida en señal de obediencia al difunto. Ponce, extrañado, solicitó a Morales que le mostrase la carta de Acquaviva en la que le comunicaba tal decisión, pero él nunca se la enseñó, porque obviamente no la tenía. Acquaviva jamás le había permitido tal cosa. Entonces, los dos escribieron a Roma, donde Alber leyó sus versiones y respondió a ambos respaldando al provincial. En primer lugar, era absolutamente necesario que Morales aclarase cuál era ese documento que podía alegar a favor de sus pretensiones, pero incluso si demostrase tenerlo, la ejecución debería esperar a la finalización de la VII Congregación General, "porque, siendo como es professo, no se puede hazer mudança ning[un] ${ }^{a}$ de su persona hasta que tengamos general". ${ }^{31}$

Morales debió de sentirse desconsolado después de fracasar en su intento. Alber le escribió con mucha claridad y le deseó que se animase a "proseguir en la gracia de su primera vocación, en la qual Dios le hará $\mathrm{m}[\mathrm{erce}] \mathrm{d}$ que proceda como hijo de la Comp[añi] ${ }^{a}$, a la qual fue seruido llamarle". Morales ya había oído lo mismo a Acquaviva, igual que otras recomendaciones tales como refugiarse en la oración o dialogar "con toda llaneza" con Ponce, a quien poco antes había intentado engañar de forma evidente. ${ }^{32}$ No pudo contener su rabia y se la demostró por escrito a Alber, pero no se atrevió a llegar más lejos. Se puso "indiferentemente" en las manos de éste, como ya había hecho con Acquaviva, aunque era claro que en ninguna de las dos ocasiones le había sido ya grata la indiferencia jesuítica, esa que san Ignacio había considerado indispensable en todas las personas que deseaban entrar en la Compañía. ${ }^{33}$

Así pues, la crisis personal que Hernando de Morales sintió en 1613 fue resuelta por Claudio Acquaviva en 1614 con una negativa a su petición de abandonar la Compañía y una recomendación de persistir en su antigua vocación a través de la oración. El inmediato control sobre su actitud reveló faltas de diversa gravedad, incluyendo algunas ciertamente reprensibles, pero ni el viejo general ni el $\mathrm{P}$. Ponce ni el vicario Alber respondieron a ninguna de ellas con medidas punitivas extremas, seguramente por no enfriar más la mermada vocación de Morales. Morales encontró cerrada la puerta de salida. Es obvio que quienes se la dejaron clausurada entendían que aquella decisión era la más correcta, pero puede tenerse por probable que si hubiesen conocido el curso futuro de los acontecimientos, habrían pensado de forma contraria.

${ }^{31}$ ARSI, Baetica, vol. 4-I, Alber a Ponce, Roma, 24 de marzo de 1615.

${ }^{32}$ ARSI, Baetica, vol. 4-I, Alber a Morales, Roma, 24 de marzo de 1615.

${ }^{33}$ ARSI, Baetica, vol. 4-I; Alber a Morales, Roma, 11 de agosto de 1615. 
Desde entonces en adelante, Morales actuó siempre como actúa alguien que, efectivamente, ha perdido total o parcialmente su vocación.

Pero ¿qué había sucedido? ¿Cómo se agotó tan rápido una vocación que los superiores al cargo habían valorado positivamente pocos años antes? Difícil pregunta ésta, como todas aquellas que pretenden ahondar en la conciencia de un hombre, máxime cuando se trata de un hombre de tiempos tan pretéritos sobre quien apenas queda documentación fragmentaria. La respuesta más adecuada parece encontrarse en una carta que Vitelleschi escribió a Morales en el verano de 1618. La carta respondía a una anterior en la que Morales se había atrevido a decir al general que no volvería a escribirle para buscar su consuelo y ayuda, aunque al mismo tiempo solicitase permiso para acudir a Roma a exponer sus quejas. Protestaba que se le hubiese encargado un ministerio que le parecía indigno de su condición de profeso y que no pudiese dedicarse a lo que él deseaba hasta que pasasen al menos cinco años. Según Morales, en aquella situación quedaba "perdido su honor". Vitelleschi respondió con ese típico tono paternalista que no renunciaba a la firmeza. Le dijo que "el honor del buen religioso está en emplearse en lo que la s[an]ta Obed[ienci]a le ocupa y esto hacerlo bien echo"; le aseguró que "la [ocupación] que aora V[uestra] R[everencia] tiene es muy propia de un Professo de la Comp[añí]" y, por tanto, "no sé porqué pueda quejarse ni mostrar la amargura que muestra". ${ }^{34}$

Ése parece haber sido el problema de fondo en el caso Morales. El honor, ese gran tirano capaz de poseer las conciencias de los hombres del siglo XVII, ese sentimiento que inspiró pasajes geniales a la literatura del Siglo de Oro y crímenes atroces a los hombres orgullosos. No hubo por medio controversias doctrinales ni problemas económicos o de otra especie; la pérdida de vocación de Morales parece haberse debido a un conflicto irresoluble entre el deber de obediencia jesuita y los impulsos del honor. ${ }^{35}$ Morales era un hombre pagado de sí mismo y quizás no le faltaba cierta razón, pues su inteligencia y su erudición eran importantes y quedan patentes al lector de sus obras escritas. Después de llegar a la cúspide de la jerarquía jesuita, se creyó merecedor de los ministerios más enjundiosos, a desempeñar en los domicilios de mayor prestigio y, sin embargo, se vio constreñido a aceptar los dictámenes de hombres a los que probablemente consideraba inferiores a él y que, sin embargo, podían imponerle su autoridad amparados por el funcionamiento

${ }_{34}^{34}$ ARSI, AH, vol. 80; Vitelleschi a Morales, Roma, agosto de 1618.

${ }^{35}$ Por eso son frecuentes las conminaciones a la obediencia a los superiores en la correspondencia de los generales con Morales, referidas a cuestiones concretas que no siempre es posible reconstruir por las características de la documentación. 
institucional de la Compañía. Era fácil alabar teóricamente el principio de la obediencia durante el tiempo de los estudios, pero no lo era tanto vivir ajustado a él durante toda la vida cuando se tiene un carácter tan orgulloso como el que caracterizó a Morales. Él solicitó su salida de la Compañía para ingresar en otra orden; evidentemente buscaba entrar en una disciplina menos jerárquica. ${ }^{36}$

\section{UN PROFESO PROBLEMÁTICO (1615-1630)}

Vitelleschi se familiarizó pronto con el nombre de Hernando de Morales, que protagonizó muchos desencuentros internos después de su fracasado intento de abandonar la Compañía. ${ }^{37}$ La muerte de Felipe III y el comienzo del reinado de Felipe IV le abrieron nuevos caminos en los que enfrentarse a sus correligionarios. Según parece, Morales consiguió integrarse dentro de la red sevillana que el conde duque introdujo en Madrid al comienzo de su valimiento ${ }^{38}$ y su implicación en estos asuntos gustó poco dentro de la Compañía. Se sabe con certeza que a fines de 1620 o principios de 1621 Morales viajó a la corte. No hay muchas noticias del caso, ${ }^{39}$ pero lo poco que se sabe permite afirmar que el traslado no fue del agrado de Vitelleschi. ${ }^{40}$ El general logró forzar el regreso de Morales a Sevilla con relativa rapidez, ${ }^{41}$ pero eso no resolvió

${ }^{36}$ La decisión también debió de estar condicionada por los aspectos económicos, puesto que en el momento de jurar votos solemnes, Morales hizo renuncia a todos sus bienes temporales. Él mismo realizó una reflexión sobre todas estas circunstancias en los memoriales que escribió en defensa del colegio de Salamanca contra Leonor Bermúdez, tanto más interesante cuanto que él se enfrentó a aquella tesitura. Véase supra nota 12.

${ }^{37}$ ARSI, Baetica, vols. 4-I y 4-II.

${ }^{38}$ Elliott, J.H. 1998: 172-173. Entre la clientela sevillana del conde duque se hallaban hombres muy cultivados, como Diego Velázquez, Juan de Fonseca, Juan de Jáuregui, el conde de la Roca, Francisco de Calatayud o Francisco de Rioja.

${ }^{39}$ Vitelleschi sólo escribió una carta a Morales cuando se encontraba en Madrid y su contenido no está relacionado con el viaje a la corte en sí: ARSI, Baetica, vol. 5-I; Vitelleschi a Morales, Roma, 22 de marzo de 1621. En las epistolae generalium de la provincia de Toledo no he sido capaz de encontrar más información sobre el episodio.

40 ARSI, Baetica, vol. 5-I; Vitelleschi a Pedro de Urteaga, Roma, 22 de marzo de 1621.

${ }^{41}$ Debió de llegar a Sevilla como mínimo en noviembre de 1621 , puesto que el 1 de diciembre de ese año firmó en la casa profesa de Sevilla su aprobación al Modo facil, y breve para rezar el Rosario por los quinze Misterios gozosos y Dolorosos, y Gloriosos: haciendo mención breue de cada Misterio por cada diez Aue Marias. Y luego el Gloria Patri, \& Filio \&c Sacado de Autores graues, Sevilla, 1622, del licenciado Gonzalo Aragonés. Utilizo el ejemplar de la Biblioteca Capitular y Colombina, 30-1-3(4). 
el problema, sino que lo agravó. Olivares mantuvo su confianza en Morales y desde Madrid le encargó negocios políticos para que se ocupase de ellos en Sevilla. La naturaleza de estos encargos no es fácil de precisar con exactitud, pero los datos disponibles permiten suponer que consistía fundamentalmente en la defensa escrita de la política real a través de memoriales de variada índole.

Por alguna razón, la colaboración de Morales con el Gobierno de Felipe IV sentó mal entre sus correligionarios. Creó mal ambiente en Sevilla ${ }^{42}$ y disgustó a Vitelleschi, que no lo había hecho salir de Madrid para que siguiera entrometiéndose en política. Fue entonces cuando pidió por primera vez mano dura con Morales. Se la demandó al P. Francisco Alemán, ${ }^{43}$ que había empezado a ocupar el provincialato de Andalucía y que con el paso de los años se convertiría en un hombre fundamental para la resolución del caso Morales. Vitelleschi le advirtió sobre "las muchas faltas que se an descubierto del P. Hernando de Morales" y las atribuyó a la poca severidad que había empleado en corregirle el P. Pedro de Urteaga cuando gobernó la casa profesa. Aseguraba que a partir de aquel momento él mismo vigilaría a Morales con atención y encargó a los superiores jesuitas en Madrid "que se lo suplique de mi parte al s[eñ]or Conde de Oliuares que no encomiende negoçios temporales al dicho P[adr]e". Alemán tendría que vedarle otros contactos personales en Sevilla, sobre todo con el canónigo Gonzalo del Campo, ${ }^{44}$ y después sacarle de la ciudad y trasladarlo a "vn Coll[egi] ${ }^{\circ}$ de los medianos, donde esté muy apartado de ocasiones". Como colofón, unas durísimas palabras harto significativas: "si él se inclinase a pasarse a otra Religión, pienso que nos estaría bien librarnos de él”. ${ }^{45} \mathrm{El}$ general empezaba a cansarse de Morales, tal vez porque comenzó a entender que su crisis vocacional no podía resolverse sólo con demostraciones de autoridad.

42 ARSI, Baetica, vol. 5-I; Vitelleschi a Francisco de Soto, Roma, 5 de septiembre de 1622.

${ }^{43}$ Francisco Alemán (Sevilla, 1566-1644). Entró en la Compañía en 1582 y profesó el 17 de enero de 1599: DHCJ, I, 45.

${ }^{44}$ Castañeda Delgado, P. 1981. "Don Gonzalo del Campo. Canónigo de Sevilla y arzobispo de Lima", en Primeras Jornadas de Andalucía y América: II 53-78. Huelva: UNIA. Del Campo fue una figura importante en la Sevilla de su tiempo. De seguro, conoció al conde duque (en cuyo tiempo consiguió el arzobispado limeño) y tuvo muchas relaciones con los jesuitas, como fundador del colegio de la Concepción, por lo que pudo haber sido un nexo entre Olivares y Morales. Agradezco al profesor José Antonio Ollero Pina sus indicaciones sobre este relevante personaje.

${ }^{45}$ ARSI, Baetica, vol. 5-I; Vitelleschi a Alemán, Roma, 5 de septiembre de 1622. 
Morales reaccionó con rebeldía cuando supo que sería expulsado de Sevilla. Antes de que Alemán procediese a enviarlo a alguna ciudad pequeña, salió precipitadamente hacia Madrid, presumiblemente con la intención de solicitar auxilio personal al Conde Duque. Vitelleschi debió de sentirse enfurecido y no permitió un agravio semejante a su gobierno. Escribió de inmediato al rector del colegio de Madrid para

que pida encarecidamente de mi parte al s[eñ]or Conde de Oliuares que tenga por bien que la Comp[añí] disponga de él [Morales] como más conviene, affirmándole que no está bien a su ex[celenci] a que el dicho $P$ [adr]e trate sus negoçios, $y$ en alcançando su beneplácito, embíe luego al P[adr]e Morales a su Prou[inci $]^{a}$.

La preferencia de Vitelleschi no era dejarlo en ella. De hecho, insistió a Alemán para que le ofreciese abiertamente el cambio a otra orden; "quiçá gustará de ello, y nos libraremos de él". ${ }^{46}$ A todas luces, había pasado el tiempo en el que Vitelleschi se mostraba dispuesto a actuar siempre con paternal afecto hacia el jerezano.

Si Alemán propuso a Morales abandonar la Compañía, y no hay razones para pensar que no lo hiciera, éste debió de rehusar tal posibilidad. No deja de ser una reacción notable, por cuanto él mismo lo había solicitado casi diez años antes. No nos es dado conocer las razones que explican ese cambio de actitud, pues todas pertenecen al ámbito de la conciencia de Morales. Acaso Alemán las supo y es posible incluso que se las comunicara a Vitelleschi, pero en caso de ser así nada ha quedado de todo eso. Lo único seguro es que, cerrada la vía de la expulsión (de momento), Morales debió abandonar Sevilla. No le resultó fácil, según confesó al general, pero éste se mostró inflexible. Defendió a Alemán por haberle obligado a mudarse de colegio, le aseguró que la decisión había sido meditada y le rogó que fuese autocrítico, pues "en causa propria cada vno se debe tener a sí por sospechoso". Le explicó que debía dejar los problemas del siglo, que no eran conformes a la condición de jesuita, y atender sólo los del espíritu, "pues a eso venimos acá":

P[adr]e mío, yo deseo mucho su quietud y consuelo de V[uestra] R[everencia], y crea que para él le importa mucho retirarse de todo punto de qualquier negocio temporal, como de cosa tan agena de nuestro Instituto, y tan contra nuestras Constituçiones y Decretos.

${ }^{46}$ ARSI, Baetica, vol. 5-I; Vitelleschi a Alemán, Roma, 3 de octubre de 1622. 
Libre de esas cadenas, podría centrarse en la oración, prepararse para el juicio divino y ayudar al prójimo a encontrar la salvación espiritual. ${ }^{47}$ Vitelleschi, consciente de que palabras como ésas ya habían resultado inútiles en el pasado, ordenó paralelamene a Alemán que impusiese a Morales un "preçepto de santa obediençia para que de ningún modo se entremeta en negoçio temporal ageno de nuestro Instituto, ni haga informaçiones en derecho çerca de negoçio çivil o criminal". ${ }^{48}$ Por lo que parece, ésta había sido la función de Morales dentro de la red clientelar de Olivares, ésta también la razón por la cual se le había alejado de Madrid y Sevilla y ésta finalmente la que produjo años después su expulsión de la Compañía. Nadie entonces podía prever las consecuencias que años después tendría la vinculación personal de Morales con el valido de Felipe IV ni su inclinación a escribir en nombre de éste.

El jerezano comenzó así un largo periplo por diversos colegios de Andalucía, donde protagonizó todo tipo de escándalos y conflictos. ${ }^{49}$ Tuvo problemas allá por donde fue: Málaga, Granada, Sevilla y sobre todo Cádiz, donde se enfangó en un enfrentamiento personal durísimo con el rector del colegio, el $\mathrm{P}$. Diego Meléndez, jerezano como él y a quien sin duda conocía, al menos por haber coincidido ambos en otros domicilios jesuitas. El colegio de Cádiz se dividió entre los partidarios de Morales y los de Meléndez y los dos bandos se enconaron de tal modo que produjeron alarma y preocupación en Roma. Vitelleschi comenzó sospechando de Meléndez, pero conforme fue recabando más información sobre el caso, llegó a la conclusión de que una vez más el principal culpable era el incorregible Morales, para quien exigió la salida inmediata de Cádiz. ${ }^{50}$

Morales abandonó efectivamente el colegio gaditano y, para asombro del mismo Vitelleschi, fue trasladado a la casa profesa de Sevilla, corazón de la provincia andaluza. El general escribió indignado al P. Juan de Casarrubios, provincial: "Quisiera yo que V[uestra] $\mathrm{R}$ [everencia] le vbiera puesto en otra parte donde estuviera con menos

${ }^{47}$ ARSI, Baetica, vol. 5-I; Vitelleschi a Morales, Roma, 31 de octubre de 1622.

${ }^{48}$ ARSI, Baetica, vol. 5-I; Vitelleschi a Alemán, Roma, 31 de octubre de 1622.

${ }^{49}$ ARSI, Baetica, vol. 5-I.

${ }^{50} \mathrm{Idem}$. La documentación sobre el conflicto gaditano es relativamente abundante y contiene detalles muy interesantes. Comenzó con una denuncia de Morales a Meléndez por haber vendido una lámpara de plata propiedad del colegio, pero, como se avisa, Vitelleschi terminó convencido de que la causa del problema era el terrible carácter personal de Morales. El general se sintió muy apenado por aquel episodio y llegó a solicitar a alguno de los implicados que actuase como un "ángel de paz" en aquellos asuntos. 
inconueniente; temo no buelua a las cosas pasadas en que allí faltó". Mucho le insistió en que había que vigilarlo estrechamente, deseando que su superior "le tenga siempre la rienda tirante y no le permitta de ningun modo que se entremeta en negoçios temporales". Pese a todas las precauciones que se tomasen, era muy probable que Morales generase incertidumbres de nuevo y en tal caso no habría que titubear a la hora de volver a sacarlo de Sevilla y llevarlo a un lugar "adonde se entienda que no podra ser de daño". ${ }^{51}$

Temores ciertos. Morales no tardó en demostrar que los asuntos mundanos seguían importándole tanto o más que el cuidado del espíritu. Por supuesto, le importaban mucho más que la opinión de Vitelleschi, que consideraba todo aquello como "cosa agena de nuestra professión". ${ }^{52}$ No sólo el general pensaba así: las críticas contra Morales comenzaron pronto a llegar desde Sevilla: "Me escriben que a dado algunos pareceres arrojados y que en una ocasión le dio contrario a lo que antes auía dicho en el mesmo caso, y que haze informaçiones en Derecho y ay reçelos de que reçibe interés por ellas". ${ }^{53}$ Esto lo escribió el general en 1630, el mismo año en que Hernando de Morales imprimió sus dos memoriales sobre las ventas de oficios en la ciudad de Sevilla, esos que han trascendido en los repertorios bibliográficos y que Domínguez Ortiz estudió. Vitelleschi se refería a ellos y, seguramente, pensaba en ellos también cuando pocos meses después pidió al provincial Francisco Alemán que sacase a Morales de Sevilla y lo pusiese en algún colegio retirado, donde podría "ocuparse en poner en orden algunas materias morales que desea imprimir". ${ }^{54}$ Morales estaba escribiendo mucho, ya lo había hecho otras veces en el pasado, e incluso en esa faceta resultaba problemático.

\section{HERNANDO DE MORALES, ESCRITOR}

La labor intelectual de Morales durante sus años en la Compañía no fue nada despreciable. Ejerció labores docentes en colegios de la orden y escribió tratados y memoriales de un interés notable. De entre toda la producción literaria de Morales que se conoce actualmente, la pieza que inicialmente suscita mayor curiosidad es un Tratado de la Esfera de Sacrobosco, especie de resumen del famoso estudio

51 ARSI, Baetica, vol. 5-I; Vitelleschi a Casarrubios, Roma, 16 de septiembre de 1628.

52 ARSI, Baetica, vol. 5-II; Vitelleschi a Juan Muñoz, Roma, 25 de noviembre de 1629.

53 ARSI, Baetica, vol. 5-II; Vitelleschi a Muñoz, Roma, 30 de julio de 1630.

${ }^{54}$ ARSI, Baetica, vol. 5-II; Vitelleschi a Alemán, Roma, 18 de diciembre de 1630. 
astronómico medieval de Juan de Sacrobosco, el De Sphaera. ${ }^{55}$ Pese al atractivo de la materia, el Tratado no es una obra de gran profundidad y seguramente fue el fruto ocasional de alguno de los ministerios docentes de Morales. En tal sentido, Morales se muestra fiel al saber escolástico más tradicional en la materia: se basa evidentemente en Sacrobosco, menciona esporádicamente a los "antiguos filósofos" y recurre a Alfonso $X$. La autoridad más reciente de entre las que cita data de la segunda mitad del siglo XIII. No hay ni rastro de las innovaciones astronómicas y físicas de Copérnico, Kepler o Galileo, ni tan siquiera de propuestas conciliadoras como la de Tycho Brahe. Sería atractivo atribuir a Morales un anticopernicanismo consciente en el tiempo de la Revolución Científica, existiendo precedentes dentro de la misma Compañía de Jesús, desde la que se recurrió a Sacrobosco para oponerse a la naciente teoría heliocéntrica. ${ }^{56}$ Lamentablemente, en el Tratado no se halla ninguna referencia explícita que permita comprobarlo.

En cualquier caso, el Tratado de la Esfera parece un caso aislado dentro de la producción literaria de Morales, dominada por escritos de carácter jurídico motivados por circunstancias concretas. No eran piezas de evasión ni de carácter académico, sino textos pragmáticos y funcionales, enormemente eruditos y perspicaces, compuestos para influir en situaciones sociales bien definidas, desde pleitos judiciales hasta discusiones políticas e institucionales. La correspondencia de Vitelleschi alude frecuentemente a la implicación de Morales en diversos conflictos legales: defendió a un hermano suyo en un juicio por asesinato, ${ }^{57}$ se enredó en el reparto de la herencia de D. Íñigo de

55 Real Academia de la Historia (RAH), 9/2795(2); Tratado de la esfera de Sacrobosco por el Padre Hernando de Morales de la Compañía de Jesús, s.f. La Academia conserva también un interesantísimo manuscrito en el que Morales analiza jurídicamente el breve de Urbano VIII De non alienandis bonis ecclesiasticis: RAH, 9/3654(41).

56 El caso más célèbre es, evidentemente, el de Christoph Clavius: Lattis, J. M. 1994. Between Copernicus and Galileo. Christoph Clavius and the collapse of Ptolemaic cosmology: Chicago: Universidad. Sin embargo, mucho más cercano a Morales se encontraba el $P$. Juan de Pineda, quien, según José Antonio Ollero Pina, también empleó a Sacrobosco ( $y$, a su vez, a Clavius) para enfrentarse al copernicanismo. Agradezco al profesor Ollero Pina que compartiese conmigo sus conocimientos en esta materia.

57 ARSI, Baetica, vol. 5-II; Vitelleschi a Jorge Hemelman, Roma, 29 de julio y 26 de agosto de 1624. La defensa de otro miembro de su familia se encuentra en Biblioteca Diocesana de Córdoba (BDC), FA 17/R.005.461/2; Por D. Diego de Morales Maldonado, veynte y quatro de Xerez de la Frontera: en el pleyto con el fiscal de la comission de cuentas de posito de la dicha ciudad de Xerez, s.f. El Catálogo Colectivo del Patrimonio Bibliográfico lo atribuye erróneamente al veinticuatro jerezano, pero es obra del jesuita. 
Córdoba, ${ }^{58}$ se inmiscuyó en un enfrentamiento interno de la familia Álvarez de Toledo... ${ }^{59}$ Como él mismo afirmó en cierta ocasión, "confiesso, señor, que [...] è visto muchos pleitos, i leído muchissimos en los Autores" ${ }^{60}$ Era todo lo contrario a lo que le recomendaba Vitelleschi, que le advirtió frecuentemente que "lo que importa es que V[uestra] $\mathrm{R}$ [everencia] no se entremeta de ningún modo en pleytos, ni negoçios temporales, sino puramente se ocupe en lo que es proprio de nuestra professión, y muéstrese siempre muy subordinado y rendido a lo que la $\mathrm{s}$ [an]ta obediençia quisiere y dispusiere de V[uestra] R[everencia]. ${ }^{61}$

Se advierte una cierta contradicción en estas críticas, puesto que más de una vez la Compañía se sirvió directamente de la capacidad jurídica de Morales para defenderse en pleitos. Así lo testimonian los impresos que Morales dedicó al conflicto entre el colegio real de Salamanca y doña Leonor Bermúdez ${ }^{62}$ o el que redactó para sostener la pretensión de la casa profesa de Sevilla de no contribuir fiscalmente al servicio de Millones. ${ }^{63}$ En estos casos no hay repugnancia en la correspondencia de Vitelleschi, evidentemente porque la actuación de Morales resultó satisfactoria para la Compañía. La incoherencia es flagrante, pero puede explicarse. Cabría la posibilidad de pensar que, sencillamente, a sus superiores no les gustaba que Morales se metiera en problemas ajenos, pero, sabedores de su valía intelectual, se sirvieron de ella cuando los problemas eran propios: su autoridad de gobierno les permitía decidir cuándo era útil el conocimiento jurídico de Morales y cuándo no. Podría pensarse también en una simple cuestión de cronología, un aspecto difícil de analizar, por cuanto los escritos en Derecho de Morales no se hallan fechados. Tal vez, los que redactó para los pleitos de la Compañía eran anteriores y cuando cundió la fama de

58 ARSI, Baetica, vol. 5-II; Vitelleschi a Jorge Hemelman, Roma, 9 de diciembre de 1625 y 8 de abril y 2 de junio de 1626. El aludido era sobrino del arzobispo de Sevilla, don Luis Fernández de Córdoba y Portocarrero. Este asuntó enfadó mucho al general, que lamentó el cuidado que le producían "los ruydos en que se a metido y nos a metido el P[adr]e Her[nan]do de Morales; raçón es que a todos nos lo den, porque tocan al buen nombre de la Comp[añí] $]^{a ” .}$.

59 ARSI, Baetica, vol. 5-II; Vitelleschi a Diego Meléndez y Juan Muñoz, Roma, 25 de noviembre de 1629. Nada menos que un pleito de la rama del marquesado de Villafranca, sostenido entre don Pedro, II marqués y ganador de la Grandeza para el título, y su hermano don Fadrique, el aclamado defensor de Bahía de Todos los Santos (Brasil, 1625).

${ }^{60}$ Morales, Segunda. Por el real colegio, cap. 5.

${ }^{61} \mathrm{ARSI}$, Baetica, vol. 5-I; Vitelleschi a Morales, Roma, 16 de noviembre de 1626.

${ }^{62}$ Véase supra nota 11.

${ }^{63}$ BUS, 110/141(3); Por la casa professa en el pleito con los milloneros y en el articulo sobre si an de obedecer al luez Conservador, s.f. 
sus habilidades, otros quisieron aprovecharlas, causando malestar en la orden. De ahí las prohibiciones.

Si se trató de una cuestión de tiempo, la tolerancia terminó hacia 1630, año en el que Morales publicó sus dos escritos jurídicos más célebres: la Respvesta ${ }^{64}$ y el Apendice. ${ }^{65}$ La guerra de Mantua se encontraba en su momento más crudo y Ambrosio Spinola había debido acudir al remedio de lo que Gonzalo Fernández de Córdoba no había logrado atajar. Mientras, la guerra de Flandes continuaba su penosa andadura y en el Imperio los ejércitos de Suecia entraban en acción contra los Habsburgo. La Monarquía necesitaba dinero y los ingresos convencionales no bastaban. La venalidad se erigió entonces en un medio de financiación alternativo. La Corona decidió vender oficios municipales y villas de los principales concejos del reino y Sevilla se convertiría en uno de los artículos más codiciados del mercado. ${ }^{66} \mathrm{El}$ cabildo recibió carta de Su Majestad en la que se le informaba del proyecto y el rechazo fue manifiesto. Por lo que parece, se buscó el apoyo doctrinal de un teólogo bien versado en este tipo de asuntos y, al menos, un nombre salió a la luz, el de Hernando de Morales. ${ }^{67}$

Sin embargo, la respuesta de Morales no fue como los capitulares esperaban. De hecho, fue todo lo contrario, una apología de la política monárquica basada en dos tesis fundamentales: 1) era necesario mantener el activismo militar en el exterior y 2) para financiarlo la Corona

${ }^{64}$ BUS, 110/141(5), Respvesta de el padre Hernando de Morales de la Compañía de lesus, a la muy noble y muy leal Ciudad de Sevilla en su ayuntamiento. En lo que se le consultò sobre si con segura conciencia, puede venir en que su Magestad venda doze mil vassallos, y un Oficio de Regidor perpetuo en cada Ciudad, y Villa, y las varas Alguaziles mayoresSevilla, 7 de febrero de 1630. El Catálogo Colectivo del Patrimonio Bibliográfico señala otros ejemplares en RAH, 9/3608(23) y 9/3763(13) y BDC, FA 17/R.005.466(32).

${ }^{65}$ BUS, 110/141(6), Apendice a la respvesta qve el padre Hernando de Morales de la Compañia de lesus dio a la muy noble y muy leal Ciudad de Sevilla, en lo que se le consultò cerca si podían con buena conciencia venir en que se vendiesen vassallos, oficios de Regidores, y varas de Alguaziles mayores, Sevilla, 10 de abril de 1630. El Catálogo Colectivo del Patrimonio Bibliográfico señala otros ejemplares en RAH, 9/3608(24) y 9/3742(47) y BDC, FA 17/R.005.466(31).

${ }^{66}$ Gelabert González, J. E. 1997. La bolsa del rey. Rey, reino y fisco en Castilla (1598-1648): 164-170 Barcelona: Crítica y 1997. "Tráfico de oficios y gobierno de los pueblos en Castilla (1543-1643)", en L. A. Ribot García y L. de Rosa (dirs.), Ciudad y mundo urbano en la época moderna: 157-186 Madrid. Actas-Istituto Italiano per gli Studi Filosofici.

67 Archivo Municipal de Sevilla, Actas Capitulares, H-1714; cabildo extraordinario, 9 de febrero de 1630. Desgraciadamente, no se menciona en ningún momento a Morales, aunque es evidente que se tomó entonces la decisión de consultarle, a tenor de su propio testimonio. 
podía utilizar legítimamente cualquier expediente fiscal que estimase oportuno. La primera tesis era una refutación del hartazgo generalizado de la población hacia la política exterior de los Austrias, la guerra de Flandes y los demás conflictos internacionales, ${ }^{68}$ es decir, "las objeciones de el vulgo, de q[ue] por aver venido los Reyes por su culpa a pobreza, no pueden quitar lo ageno a los suyos, y q[ue] dexe las guerras, y perder a Flandes, q[ue] tanto à empobrecido a España, y de q[ue] tan poco util se sigue, y tantos gastos y daños se recrecen",69 el deseo de que "desampare su Magestad a Italia, y a Flandes, y se recoja a Espana, y la conserve, y se contente con ella y con las Indias, y passe como sus primeros exemplares, que no tenian tanto, y les sobrava mas". ${ }^{70}$ Frente a esta opinión, Morales luchó con varios argumentos: la imagen de España como obligada defensora de la fe, la necesidad de conservar la reputación de la nación o la conveniencia de mantener la guerra en el exterior para prevenir la seguridad en el interior. Así, en la Respuesta se encuentra esta ponderación de

la importancia de conservar a Flandes en sujecion, y obedie[n]cia de la Fè Catholica, y de el govierno de España, y con razones, q[ue] à cualquier pecho noble y Christiano movieran a ponerse en aprietos, para alentar a su Rey, no solo a co[n]servar lo posseydo, sino a restaurar lo perdido, y castigar la desmesura, orgullo, y atrevimientos experimentados, con detrimento de la Fé de lesu Christo, y de la reputacion y interes de nacion tan respetada, y reconocida en el mundo como la Española. ${ }^{71}$

Igualmente, en el Apéndice se lee esta advertencia:

$Y$ decir, que se dexe Italia y Flandes con tanta mengua y menoscabo de el crédito de las armas Españolas, es inescusable error, porque si con estar aora enfrenados los enemigos de nuestra gloriosa Monarquia, por el imperio que sobre ellos, o sus vecinos se ocupa tumultuan, y se atreven; quando se vean solos, poderosos, y sin miedo de guerras en sus casas, y menguas, gastos, y menoscabos que a las guerras domesticas se siguen, [¿]que paz se gozarà en España de ellos tan aborrecida y emulada? [¿]Que mares estarán seguros? [¿]que Indias se contrataran sin contradicion poderosa? ${ }^{72}$

68 Éste fue el aspecto que, como quedó dicho, más interesó a Domínguez Ortiz, Alteraciones andaluzas, pp. 44-45.

${ }^{69}$ Respuesta, cap. 18.

${ }_{71}^{70}$ Apéndice, cap. 21.

${ }^{71}$ Respuesta, cap. 19.

72 Apéndice, cap. 21. La retahíla sigue y es interesante observar cómo tiene muy presente los efectos de la guerra sobre el comercio internacional y 
Por supuesto, todos eran argumentos frecuentes en el pensamiento belicista que triunfó en la corte durante el tránsito entre los reinados de Felipe III y Felipe IV. ${ }^{73}$

La segunda tesis era una consecuencia necesaria de la primera, pues el sostenimiento de la guerra exterior requería una elevada financiación que sólo podía satisfacerse desde una posición fiscal fuerte. Una posición como la que había adoptado la Monarquía a la hora de vender oficios y villas municipales. ¿Podía hacerlo legal y legítimamente? Morales reconoció al concejo hispalense que tenía razones para resistirse a las pretensiones monárquicas. Constaba fehacientemente que había habido "trato entre vuestra señoría y su Majestad" para que no se pudiesen vender vasallos ni acrecentar oficios y ese acuerdo obligaba a Felipe IV. Era una condición de los servicios de Millones aprobados en Cortes. El jesuita estuvo dispuesto a conceder: "quando interviene contrato entre los súbditos y su Principe, es notorio, que le corre obligación a observar lo contratado". Así lo aseguraba una rica tradición teológica y jurídica a la que Morales citaba con profusión y la conclusión quedaba reforzada por el trato de favor que Sevilla había dispensado a la Corona con "interesses y servicios tan grandiosos" como los que había puesto en sus manos. Tan leales súbditos merecían la mejor consideración y aquélla no lo era. ${ }^{74}$

Pese a la claridad de esta doctrina, Morales reconoció a los capitulares que su opinión se inclinaba hacia el lado de la Monarquía. ¿Cómo podía justificarse que, en esta ocasión, el Rey no respetase lo contratado con sus vasallos? Inmediatamente, viene a la mente el concepto Absolutismo, pero no era eso en lo que pensaba el jesuita. De hecho, Morales reconocía que Felipe IV era un "Principe absoluto", condición que merecía "por no reconocer superior en su dominio, e Imperio temporal". Sin embargo, tanto poder no le bastaba para ignorar el Derecho natural; siguiendo a Baldo, podía argüir: "esta obligación no era civil, por ser el Principe superior a la ley, sino natural". Y mucho menos podía servirle para soslayar el ejemplo de Dios, que "quiso para exemplo

colonial: "[¿]que armadas serán bastantes a defender las flotas? Y si quando estas se retardan y detienen aun por corto tiempo mas de el determinado, el comercio gime, la pobreza aprieta, la necesidad aflige y todo es suspensión, tristeza, y luto. Quando toda Flandes sea de hereges, y por la comodidad de armar baxeles en aquellas regiones, se especen los piratas, se engruessen las esquadras, con la codicia de las Indias, y intenten ocuparlas, [¿] que gastos bastaran para ofenderlos con fruto, y assegurallas sin recelo?"

${ }^{73}$ Elliott, J. H. 1998: 83-94 y, previamente, 1982. "Introspección colectiva y decadencia en España a principios del siglo XVII", en J.H. Elliott (ed.), Poder y sociedad en la España de los Austrias: 198-223. Barcelona: Crítica.

${ }^{74}$ Respuesta, caps. 1-8. 
de los Principes, contratar con Abraham, y los demas Patriarchas, obligandose, y cumpliendo sus pactos y promesas". ${ }^{75}$

No era el poder absoluto de Felipe IV lo que podía sancionar las ventas municipales, sino otro concepto que llegaría a arraigar fuertemente en la cultura política española, el de la necesidad. ${ }^{76}$ En aquel 1630, Morales pensaba en aquella teoría como una forma de "inovar" y no es extraño que lo concibiera así. Una sociedad tradicionalista como la española del XVII contemplaba las novedades con desconfianza, pero el régimen del Conde Duque, que estaba detrás de los escritos de Morales, había hecho de la innovación política su seña de identidad. ${ }^{77}$ Sin embargo, la inagotable cultura libresca de Morales no dejaba de poseer referencias a las que acudir para justificarse $y$, finalmente, concluir:

que tratando el caso presente, y aviendo apretado al Principe para que estè al contrato, y no venda vasallos, limitan su doctrina con la comun de los Doctores exceptuando, sino es en caso de urgente necesidad pro bono pacis, \& in utilitatem publicam, y mas si se atraviessa la Fè.

Por tanto, no era la voluntad subjetiva de un monarca situado por encima de la ley lo que podía romper los pactos firmados con el Reino. Eran las condiciones objetivas de una determinada coyuntura las que excepcionalmente podían permitirlo, siempre tomando como referencia el bien común y, antes que cualquier otra cosa, el provecho de la $\mathrm{Fe}$ católica $^{78}$.

Desde tales presupuestos, el cabildo de Sevilla tendría que resignarse. Las apuradas circunstancias de 1630 eran de las que aconsejaban tomar medidas de tal calibre. Por tanto, puesto que "no ay otro medio ni camino de presente con que socorrer efectiva $y$ prestamente el bien publico, defensa de la Iglesia, y Fè Catholica: juzgo q[ue] no se puede contravenir a la determinación Real, y que se deve o darle los efectos que pide en otra cosa tan pronta, o venir en la venta de lo propuesto". No se trataba del capricho de un monarca ensoberbecido; Felipe IV debía hacer sencillamente "lo que mejor viere que conviene, y

75 Ibid., cap. 2

76 Andújar Castillo, F. 2008. Necesidad y venalidad. España e Indias, 1704-1711: Madrid: Centro de Estudios Políticos y Constitucionales, que demuestra la vigencia de la teoría de la necesidad en el siglo XVIII y su recurrente vinculación con prácticas venales.

77 Elliott, J.H. 1982, 218-219.

${ }^{78}$ Respvesta, caps. 9 y 10. 
pide la necessidad" ${ }^{79}$ Ése era el corazón doctrinal de la Respuesta y en el mismo sentido afirmó en el Apéndice: "la necessidad trae consigo anexa la dispensacion". ${ }^{80}$ Todo debía someterse al imperio de la necesidad, que era la necesidad común que representaba la Monarquía.

La abnegación que Morales postulaba ante los sacrificios fiscales recuerda por su contenido e incluso por su estilo a las famosas filípicas del conde duque de Olivares por la causa suprema de la Monarquía. ${ }^{81}$ Sin duda, el contenido de aquellos escritos estuvo influenciado e inspirado por las opiniones y directrices de su viejo amigo, el valido. Sin embargo, esta opinión oficialista era una opinión de minorías. Castilla clamaba contra el peso de la fiscalidad regia, en la que veía una de las razones fundamentales de su declinación económica. ${ }^{82}$ Por eso la Respuesta y el Apéndice obtuvieron tan mala prensa que llegaron a oídos de Vitelleschi como "pareceres arrojados" e "informaciones en Derecho", relacionados por sus detractores con sospechosos cambios de opinión y supuestas remuneraciones económicas que podrían explicar estos vaivenes. Por eso también, Vitelleschi extendió al gobierno provincial andaluz la orden de sacar a Morales de Sevilla. Y por eso, finalmente, se produciría la expulsión definitiva de Hernando de Morales de la Compañía de Jesús, acaecida en 1631, año decisivo en los conflictos entre el Gobierno de Felipe IV y el estamento eclesiástico sevillano.

\section{LA EXPULSIÓN (1631)}

A lo largo de su carrera como tratadista jurídico, Morales defendió en alguna ocasión la inmunidad del clero en materia tributaria, aunque también puso su pluma al servicio de la causa contraria, avalando la capacidad de la Monarquía para imponer su autoridad en caso de necesidad. Ciertamente, cuando había apoyado la inmunidad eclesiástica lo había hecho de forma interesada o forzada, puesto que había defendido específicamente a la casa profesa en la que residía frente al oneroso pago de los Millones. En cualquier caso, no es descartable una cierta evolución en el tiempo, ardua de precisar por la mencionada dificultad de situar cronológicamente los textos jurídicos de Morales. Lo que está claro es que a la altura de 1630 Morales se había manifestado claramente partidario de las doctrinas favorables a la Corona,

${ }_{80}^{79}$ Ibid., cap. 9

${ }^{80}$ Apéndice, cap. 19.

${ }^{81}$ Elliott, J. H. 1998.

${ }^{82}$ Marcos Martín, A. 2006. "¿Fue la fiscalidad regia un factor de crisis en la Castilla del siglo XVII?", en Geoffrey Parker (coord.), La crisis de la Monarquía de Felipe IV: 173-253. Barcelona: Inst. Simancas-Crítica. 
potenciando o retomando su vinculación con la clientela olivarista, en cuya órbita había figurado desde comienzos del reinado de Felipe IV.

Morales se destacó por su monarquismo en un momento muy difícil. La Corona consiguió finalmente el permiso del Reino para enajenar oficios y villas municipales; Bartolomé Spinola se encargó de la operación y llegó a vender las veinticuatrías sevillanas por 8.000 ducados, sólo superadas por las regidurías de Madrid, que valieron 11.000 . $^{83}$ Pero no todo quedó ahí; en 1631 el alto clero sevillano se enfrentó duramente a las apetencias fiscales de la Monarquía y sus doctrinas justificadoras, entre ellas la teoría de la necesidad, convertida en punto central de la discusión fiscal de aquellos días. El Gobierno intentó sustituir el servicio de Millones por el estanco de la sal y el cabildo catedralicio sevillano se destacó en la lucha contra él o, al menos, contra su aplicación al clero. El nuncio papal, monseñor Cesare Monti, se alineó con la Iglesia sevillana; entendía que el estanco de la sal era un intento del Gobierno de marginar al Papa y romper la jurisdicción eclesiástica, alegando como excusa el argumento de la necesidad. Monti, que se encontraba en Madrid, se basaba en denuncias formuladas por el capítulo sevillano ante el concejo, según las cuales el Gobierno contaba con los servicios de "theologi alchilati per interese e pretensioni" para difundir las doctrinas que le interesaban. ${ }^{84}$ También provenían de la capital andaluza las quejas que recibió Vitelleschi sobre los supuestos sobornos aceptados por Morales para escribir sus "pareceres arrojados" e "informaciones en Derecho". Evidentemente, en ambos casos se hablaba de él.

Morales estaba sosteniendo la línea gubernamental que execraban el nuncio y el Papado, el clero capitular sevillano y, sin duda, muchos jesuitas, pues ya la casa profesa había repugnado el pago de los Millones, mal sustituidos por el estanco de la sal. La presión contra él empezaba a ser excesiva. Los conflictos personales en los que siempre se había involucrado se estaban convirtiendo en disputas institucionales de altísimo nivel. Coincidiendo con la crisis política sevillana, Vitelleschi se decantó finalmente por deshacerse de él. En su opinión, Morales había llegado a merecer un "buen castigo" y entendía por tal la invitación a "pasarse a otra religión". Escribió al P. Francisco Alemán, todavía a cargo del provincialato andaluz, y le ordenó que discutiese el asunto con sus consultores y "si jusgaren que será bien combidarle con la liçençia que para esto es menester, hágalo". Pese a todo, Vitelleschi señalaba unos límites, impuestos por la dignidad corporativa de la Compañía de Jesús. Si se aprobaba su dimisión, Morales tendría que pasar a otra

${ }^{83}$ Gelabert González, J. E. 1997, 164-170.

${ }^{84}$ Gelabert González, J. E. 2001: 42-43 y 46-47; Fortea Pérez, J. I. 2008: 147. 
orden y "si no hiziere professión en la Religión donde entrare, tiene obligaçion de boluerse a la Comp[añí] ${ }^{a}$, como professo que es de ella". En cualquier caso, había que obligarle inmediatamente a abandonar Sevilla y mudarse a un colegio pequeño, "adonde esté retirado de ocasiones y atienda solamente a su estudio y a confessar hombres". ${ }^{85}$ De hecho, se había ordenado así meses atrás, pero Morales no había obedecido.

La decisión de Vitelleschi recayó sobre un pequeño espacio en el que las relaciones personales se habían enturbiado en un grado extremo. Una nueva carta del general a Alemán deja a la luz las tremendas tensiones que en aquellos momentos estaban dividiendo a los jesuitas sevillanos. Decía Vitelleschi:

Las faltas, inquietudes y grande desunión de algunos de la Casa Professa y Collegio de Seuilla me tienen harto lastimado y con mucho cuydado, espeçialmente las de la dicha Casa. Mucho temo que no se an de remediar del todo hasta que v[uestra] r[everencia] saque de ella algunos de terribles condiçiones y naturales (no los nombro porque es muy notorio quiénes son), porque por bueno, $s[a n]^{\text {to }}$ y prudente que sea el prepósito que de nueuo entrare a gouernarla, no a de poder tenerla y conseruarla con la paz y vnión que conviene, mientras vbiere en ella tales sujetos, que los vnos a los otros se an de estar mordiendo e inquietando y así jusgo por necessario que v[uestra] r[everencia] los vaya sacando y diuidiendo unos de otros.

Pese a su voluntad de no dar nombres, dos salieron a relucir en la carta del general: Hernando de Morales y Diego Meléndez. En efecto, Meléndez, el encarnizado enemigo gaditano de Morales, había sido trasladado a la casa profesa de Sevilla. En aquel momento de máxima rivalidad doctrinal política, se reavivaron los antagonismos personales más envilecidos. Meléndez llegó a denunciar a Morales ante la Inquisición y Vitelleschi, escandalizado por el acto, intentó reaccionar ordenándole su salida inmediata de la ciudad. ${ }^{86}$ Pero ya era tarde.

En esta situación límite el caso Morales estalló definitivamente. El jerezano tenía muchos, demasiados enemigos y cuando éstos supieron que Vitelleschi empezaba a sugerir la idea de apartarlo de la Compañía,

85 ARSI, Baetica, vol. 5-II; Vitelleschi a Alemán, Roma, 8 de julio de 1631. Con el mismo ordinario envió una carta dirigida a Morales en la que lo conminaba a que "[vuestra reverencia] se ponga con mucha indifferençia en las manos del P. Prov[inci] ${ }^{\text {al }}$ y cumpla muy puntualmente lo que le dixere".

${ }^{86}$ ARSI, Baetica, vol. 6-I; Vitelleschi a Alemán, Roma, 12 de agosto de 1631. 
no dudaron en tergiversar sus órdenes en detrimento de la considerada oveja negra. Francisco Alemán se hizo cargo del asunto y lo discutió con sus consultores, como Vitelleschi le había pedido; pero a diferencia de lo que le había sugerido el general, no debatió con Morales, no intercambió impresiones con él y no le abrió ningún abanico de posibilidades. No le propuso el cambio a otra orden; sencillamente lo expulsó de la Compañía, sin más. Lo que no hizo un general lo decidió un provincial. Como es natural, la decisión sorprendió negativamente a Vitelleschi y así se lo hizo saber a Alemán:

Auiendo considerado de espaçio y consultado con los $\mathrm{P}[\mathrm{adr}]^{\mathrm{es}}$ assistentes todo lo que v[uestra] r[everencia] me escribe acerca de la expulsión del P. Her[nan $]^{\text {do }}$ de Morales, digo que no se debía de auer despedido ni vbo bastante causa para la epiqueya, pues se pudieran auer puesto medios para entretener un negoçio tan graue como éste hasta auisarme y esperar mi resoluçión.

Sin embargo, ninguna represalia seria esperaba a Alemán y sus consejeros. Antes al contrario, Vitelleschi condescendió tácitamente con su decisión e incluso les felicitó por haber actuado según les había dictado la conciencia: "por esta vez yo confirmo lo hecho y quedo muy satisfecho de que v[uestra] r[everencia] hizo quanto se le ofreció en orden al buen açierto de lo que se trataba". ${ }^{87}$

¿Cómo puede explicarse este giro final? ¿Qué llevó a un hombre recto y autoritario como Vitelleschi a felicitar a un subordinado por haberse excedido en la resolución de un caso de tanta gravedad como la expulsión de un profeso, burlando su mando supremo? La explicación parece encontrarse en otras siete cartas que el mismo ordinario del 20 de octubre trasladó a Sevilla. Iban dirigidas a jesuitas residentes en la capital andaluza que habían escrito a Roma apoyando la expulsión de Morales. Según parece, todos coincidían en la satisfacción generalizada que había suscitado en Sevilla la resolución de Alemán. Al más eminente participante de aquella campaña epistolar, el P. Juan de Pineda, ${ }^{88}$ autor de notables escritos teológicos y espirituales, Vitelleschi reconoció: "Huélgome de que vniuersalmente aya parecido tan bien como v[uestra] r[everencia] y otros me escriben la resolución que se tomó açerca de la expulsión del P. Her[nan $]^{\text {do }}$ de Morales". ${ }^{89}$

${ }^{87}$ ARSI, Baetica, vol. 6-I; Vitelleschi a Alemán, Roma, 20 de octubre de 1631.

88 Juan de Pineda (Sevilla, 1557-1637), entró en la Compañía en 1571 y profesó en 1592: $D H C J$, IV, p. 3.138.

89 ARSI, Baetica, vol. 6-I; Vitelleschi a Juan de Pineda, Roma, 20 de octubre de 1631. 
Aquellas palabras eran sinceras. Seguramente fue la fuerza del número, de la mayoría, lo que consiguió que Vitelleschi pasara de puntillas sobre aquella transgresión de la cadena de mando. El general comprendió que Alemán había actuado presionado por el entorno, incluso aunque no le faltaran deseos personales de librarse de Morales. Había sido la comunidad la que había expelido al miembro indeseado. Institucionalmente, era posible que el general revocase la decisión del provincial y permitiese volver a Morales a algún domicilio, pero ¿para qué? ¿Para que a los pocos meses Morales volviese a protagonizar más incidentes con cualquier otro compañero?, ¿para que volviesen a tensarse los ánimos y aflorasen nuevas disputas internas?, ¿para que Morales siguiese defendiendo las doctrinas gubernamentales $y$ entrometiéndose en pleitos y negocios temporales?, ¿para que el prestigio de la Compañía de Jesús volviese a sufrir las consecuencias de todo ello? No tenía sentido. La gravedad de una expulsión había hecho titubear al gobierno romano, pero los jesuitas sevillanos habían estallado en las dificilísimas circunstancias de 1631; no habían podido aguantar más y aprovecharon la primera ocasión que tuvieron para hacer lo que tanto deseaban. Mejor era dejarlo así.

\section{CONSIDERACIONES FINALES}

La pista documental de Hernando de Morales se desvanece a partir de este momento. Vitelleschi nunca volvió a escribirle y jamás volvió a figurar en el catálogo de ningún colegio jesuita. Fuera de la institución en la que habían transcurrido casi cuarenta años de su vida, no era más que un súbdito anónimo de Su Majestad, detectable tan sólo en la documentación parroquial o notarial. ¿Dónde?, ¿en Sevilla?, ¿en su Jerez natal? No lo sabemos y es posible que no lo sepamos nunca. El recuerdo de Hernando de Morales se reduce así al amplio fragmento de su vida que se desarrolló dentro de la estructura jesuítica e incluso éste ha pasado casi desapercibido durante siglos. Todo porque, después de la expulsión, vino también la damnatio memoriae. La Compañía de Jesús se esforzó por olvidar a Morales. No había lugar para él, y es lógico que así fuera, en obras que pretendían ser más edificantes que auténticamente históricas. Los dos espejos del P. Antonio de Solís, crónica dieciochesca de la casa profesa hispalense, no lo menciona ni una sola vez, ni siquiera cuando registra los acontecimientos de 1630 y 1631. Del primero alaba la fastuosidad de las fiestas de aquel año y añade: "los ministerios y funciones de Casa corrieron con igual felicidad". De 1631, año convulso como pocos, se limita a afirmar: "no ocurren en él más que los ordinarios ministerios y fiestas. Baste decir que en nada decayeron de las anteriores". ${ }^{90}$ La historia de Hernando de Morales y de

90 Solís. A. de (Molina García, L., ed.). 2010. Los dos espejos. Historia de la Casa Profesa de la Compañía de Jesús en Sevilla durante sus dos 
todos los odios y disputas que germinaron en torno a él había sido convenientemente eliminada.

Esa historia es la de un religioso de sólida formación intelectual y desenfrenado orgullo, que ascendió a la cúspide de la jerarquía jesuita gracias a sus dones personales pero perdió rápidamente su vocación por no saber soportar la autoridad de sus superiores. Puesto que sus deseos de abandonar la orden no fueron satisfechos, Morales se convirtió en un profeso problemático durante muchos años, más aun después de que se integrara en la red personal del conde duque de Olivares, que supo apreciar su talento. La alianza con el valido no gustó ni al gobierno romano ni a muchos de sus correligionarios y Morales se vio impelido a alejarse de la corte y los círculos del poder. Sin embargo, en los años de la "gran depresión", cuando la crisis de Mantua confluyó con la guerra en los Países Bajos y la Monarquía buscó soluciones fiscales para salir del atolladero, Morales puso de nuevo su pluma al servicio del Rey y contribuyó a la creación de una teoría de la omnipotencia regia en circunstancias de necesidad que salvaba las limitaciones teóricas que supuestamente ataban incluso a los monarcas absolutos. De hecho, se construía un Absolutismo fiscal desde la negación aparente del mismo, sentando las bases de una doctrina que se proyectaría, al menos, hasta el siglo XVIII. Aquello fue la gota que colmó el vaso: Morales quedó en una posición muy delicada en una ciudad donde -además del vasallo anónimo, del "vulgo" con sus "objeciones"- el concejo, el consulado de cargadores $y$, finalmente, el clero capitular se manifestaron virulentamente contra las gabelas que atentaban contra sus privilegios y su menguado nivel de riqueza. El estanco de la sal se hundió pronto y al mismo tiempo cayó en desgracia su defensor sevillano, Morales, por mor de un proceso de expulsión ensañado, que reveló las fuertes reservas que había llegado a suscitar entre los demás jesuitas. Después, lo olvidaron completamente.

La vida de Hernando de Morales aporta noticias nada despreciables al conocimiento de las tensiones internas que produjo la crisis internacional de 1629-1631. La verdad es que sus obras no reflejan una simple opinión personal frente a la condena del autoritarismo fiscal, más generalizada socialmente. En realidad, la Respuesta y el Apéndice son una de las muestras más elaboradas intelectualmente de las doctrinas que pretendieron justificar teóricamente los impulsos autoritarios de la Corona en una de las crisis más agudas del siglo XVII. Las conexiones clientelares con el conde duque son tan abundantes que no dejan lugar a duda respecto a que el contenido era de inspiración

primeros siglos, 1550-1767: 190-191 Sevilla: Compañía de Jesús-Fundación Focus-Abengoa. 
gubernativa ${ }^{91}$ y que Morales sencillamente desarrolló las ideas, dándoles consistencia teológica y jurídica. ${ }^{92}$ Desde esta perspectiva, la expulsión de Morales deja de ser el simple acontecimiento de una vida cualquiera y se convierte en un indicio más de la contundencia de la reacción antifiscal del clero sevillano, aunque en el hecho se entrelazaran otras razones personales.

La expulsión es también un medio para ilustrar con mayor nitidez las pautas de funcionamiento de la Compañía de Jesús ante este tipo de conflictos internos. En el caso Morales dos cosas llaman la atención inicialmente: 1) que se le denegara durante tanto tiempo su voluntad de salir de la orden y 2) que el hecho se produjera al fin en 1631, de forma tan precipitada y confusa. Todo se puede aclarar. De hecho, lo primero no fue más que una aplicación rigidísima del contenido de las Constituciones. Estaba en la mano del generalato decidir la expulsión y, conociendo que tales resoluciones debían ser pausadas y muy raras en los tramos elevados de la jerarquía, se respondió negativamente. Pero no era un autoritarismo arbitrario. Lo explica la correspondencia de Acquaviva y Vitelleschi, que abunda en invitaciones a Morales de volver hacia su vocación primera. No hubo en los generales un deseo ciego de imponerse, sino un intento de salvar algo precioso para los jesuitas: la vocación religiosa, el deseo de vivir en la disciplina ignaciana, el compromiso de ayudar las almas. Morales había llegado hasta la profesión definitiva; no era un sujeto de baja calidad, sino todo lo contrario y era lógico luchar por salvar ese patrimonio espiritual, antes de desecharlo por completo y perderlo definitivamente.

Esta aplicación mecánica de las Constituciones sólo podía ser posible si el súbdito cumplía igualmente con la parte que le correspondía: obedecer. Morales debería haber aceptado indiferentemente la decisión de sus generales, pero no sucedió así. La lucha por salvar su vocación, al final, sólo podía librarla él y no tenía ninguna intención de hacerlo. Una

91 Según el nuncio Cesare Monti, el coordinador de los teólogos promonárquicos fue otro jesuita, el famoso confesor real Hernando de Salazar, SI: Elliott, J. H. 1998: 477. Salazar desarrolló una intensa actividad política en la corte, de la que interesa aquí recordar su apoyo a célebres expedientes fiscales, como el del papel sellado, cuya autoría incluso se le ha atribuido. Véase Lozano Navarro, J. 2005. La Compañía de Jesús y el poder en la España de los Austrias: 199-215 y 225-237 Madrid: Cátedra. Desgraciadamente, no he podido encontrar ningún rastro documental que establezca conexiones concretas entre Salazar y Morales.

92 En este sentido deberían figurar en el conjunto de una literatura promonárquica cuya importancia como género tal vez no ha sido destacada con suficiencia. Fortea Pérez, J. I. 2008: 155 cita la Alegación sobre el desacato de un clérigo a ciertos ministros de Álvaro de Oca y Gemidos de la Iglesia y Religión Católica del doctor Balboa. 
vez que hubo conocido la auténtica realidad de la vida religiosa, comprendió perfectamente que su concepción del servicio a Dios chocaba frontalmente con el acusado sentido de la jerarquía, la autoridad y la obediencia que imperaba en la Compañía de Jesús. Se había equivocado de orden y quiso mudarse a otra. Puesto que no se lo permitieron, tuvo la prudencia de no tomar una solución drástica, pero durante los siguientes años incurrió repetidamente en un comportamiento poco correcto. No es cuestión de trazar juicios de valores subjetivos, ni sobre Morales ni sobre la orden a la que vivía sujeto; sencillamente, su comportamiento no se adecuó a lo dispuesto en el Instituto de la Compañía, que él libremente había jurado respetar.

La contradictoria pertinacia de los generales y de Morales generó un punto muerto en el que los grandes sacrificados eran los correligionarios próximos a Morales. Ellos debieron sufrir a diario su incorregible carácter, mientras Roma se permitía desde la lejanía el lujo paternal de la paciencia. Apareció así, poco a poco, una disparidad de criterios entre el gobierno central, las autoridades provinciales y las comunidades jesuitas locales que abocaron a una ruptura de la cadena de mando como solución final del problema Morales. Solución apartada de los presupuestos teóricos de las Constituciones, aunque en el fondo la grave decisión tomada por Francisco Alemán no significase una ruptura profundísima con los deseos de Roma. Vitelleschi ya había expresado sus deseos de que Morales se mudase a otra orden, ya había dado el primer paso apuntando la posibilidad de algo parecido a lo que se terminó haciendo; no fue blanco contra negro. Aun así, Vitelleschi no había autorizado la expulsión directa y le pareció muy excesiva cuando supo su resolución y ejecución inmediata. Hubo una auténtica imposición de la periferia sobre el centro, un triunfo de las autoridades provinciales y la comunidad local sobre el gobierno romano. $Y$ más aun, siendo éste consciente de lo que había sucedido, se plegó a los hechos consumados.

Se puede así matizar al menos un concepto extremo del sentido jesuítico de la jerarquía: es ingenuo imaginar la maquinaria de la orden como un circuito vertical en el que realmente todas las órdenes fluyesen de arriba abajo, conociendo un respeto escrupuloso o imponiéndose con autoridad sobrada en caso de resistencias. El estudio del caso Morales revela una conclusión que parece bastante clara: la comprensión de la Compañía como sistema institucional burocratizado no puede obtenerse exclusivamente desde el conocimiento de los códigos escritos contenidos en el Instituto. Tampoco basta con conocer el organigrama de poder establecido que iba desde la cúpula romana hasta los domicilios. Sólo el estudio detallado de muchas vidas jesuíticas como la de Hernando de Morales podría fijar los comportamientos institucionales realmente significativos dentro de la Compañía, que no deben suponerse 
homogéneos en el tiempo y tampoco en el espacio. Hay que analizar la práctica cotidiana del poder.

\section{BIBLIOGRAFÍA}

Andújar Castillo, F. 2008. Necesidad y venalidad. España e Indias, 1704-1711: Madrid: Centro de Estudios Políticos y Constitucionales.

Aldea Vaquero, Q. 1961. Iglesia y Estado en la España del siglo XVII: Santander: U. Comillas.

Aldea Vaquero, Q. 1990. "Política interior: oposición y resistencia. La resistencia eclesiástica”, en J. H. Elliott y Á. García Sanz (coords.), La España del Conde Duque de Olivares: 399-414. Valladolid: Universidad.

Astrain, A. 1916. Historia de la Compañía de Jesús en la asistencia de España. Tomo V: Vitelleschi, Carafa, Piccolomini, 1615-1652: Madrid: Razón y Fe.

Castañeda Delgado, P. 1981. "Don Gonzalo del Campo. Canónigo de Sevilla y arzobispo de Lima", en Primeras Jornadas de Andalucía y América: II 53-78. Huelva: UNIA.

Domínguez Ortiz, A. 1973. Alteraciones andaluzas 1647-1652: Madrid: Narcea.

Domínguez Ortiz, A. 1985. Las clases privilegiadas en el Antiguo Régimen: Madrid: Istmo.

Elliott, J. H. 1982. "Introspección colectiva y decadencia en España a principios del siglo XVIl", en J.H. Elliott (ed.), Poder y sociedad en la España de los Austrias: Barcelona: Crítica.

Elliott, J. H. 1998. El conde duque de Olivares. El político en una época de decadencia: Barcelona: Grijalbo Mondadori.

Fortea Pérez, J. I. 2008. "La gracia y la fuerza: el clero, las ciudades y el fisco en la Monarquía Católica (1590-1664)", en J. I. Fortea y J. E. Gelabert (eds.), Ciudades en conflicto (siglos XVI-XVIII): Valladolid: Junta de Castilla y León-Marcial Pons. 
Gelabert González, J. E. 1997. La bolsa del rey. Rey, reino y fisco en Castilla (1598-1648): Barcelona: Crítica.

Gelabert González, J. E. 1997. "Tráfico de oficios y gobierno de los pueblos en Castilla (1543-1643)", en L. A. Ribot García y L. de Rosa (dirs.), Ciudad y mundo urbano en la época moderna: Madrid: ActasIstituto Italiano per gli Studi Filosofici

Gelabert González, J. E. 2001. Castilla convulsa (1631-1652): Madrid: Marcial Pons.

González Beltrán, J. 1998. Honor, riqueza y poder. Los veinticuatro de Jerez de la Frontera en el siglo XVIII: Jerez: Ayuntamiento.

González Beltran, J. 2001. "Constitución y reproducción de una oligarquía urbana: los veinticuatro de Jerez de la Frontera en el siglo XVII". Revista de Historia Moderna: Anales de la Universidad de Alicante 19: 355-384.

Lattis, J. M. 1994. Between Copernicus and Galileo. Christoph Clavius and the collapse of Ptolemaic cosmology: Chicago: Universidad.

Lozano Navarro, J. 2005. La Compañía de Jesús y el poder en la España de los Austrias: Madrid: Cátedra.

Lynn Martin, A. 1986. "Vocational Crises and the Crisis in Vocations among Jeuits in France during the Sixteenth Century". The Catholic Historical Review 72/2: 201-221.

Marcos Martín, A. 2006. "¿Fue la fiscalidad regia un factor de crisis en la Castilla del siglo XVII?", en Geoffrey Parker (coord.), La crisis de la Monarquía de Felipe IV: 173-253. Barcelona: Inst. Simancas-Crítica.

Ollero Pina, J. A. 2011. "Cerrad el pico al «Pico de oro». Fr. Hernando de Santiago, un predicador político en la España de Felipe III". Erebea. Revista de Humanidades y Ciencias Sociales 1: 281-313.

O’Neill, Ch. y Domínguez, J. Ma . (dirs.) 2011. Diccionario Histórico de la Compañía de Jesús: Madrid-Roma: Universidad Comillas-IHSI.

Pavone, S. 2011. "I dimessi dalla Compagnia negli anni del generalato di Francesco Borgia: una nuova questione storiografica", en E. García Hernán y María del Pilar Ryan (eds.), Francisco de Borja y su tiempo. Política, religión y cultura en la Edad Moderna: 465-479. Valencia-Roma: Albatros-IHSI. 
Simón Díaz, J. 1975. Jesuitas de los siglos XVI y XVII: escritos localizados: Madrid: FUE.

Simón Díaz, J. 1992. Bibliografía de la Literatura Hispánica: Salamanca: CSIC

Sommervogel, C. 1960 [1894]. Bibliothéque de la Compagnie de Jésus: Lovaina: Biblioteca Jesuita. 